\title{
Clinical Characteristics, Complications and Predictors of Outcome of Hospitalized Adult Sudanese Patients with COVID-19 and Malaria Co- Infection in Sudan, a Multi-Center Retrospective Cross-sectional Study
}

\author{
Khabab Abbasher Hussien Mohamed Ahmed (D Khabab9722@gmail.com ) \\ University of Khartoum, Faculty of Medicine https://orcid.org/0000-0003-4608-5321 \\ Elfatih A. Hasabo \\ University of Khartoum, Faculty of Medicine https://orcid.org/0000-0001-9727-8620 \\ Mazin S. Haroun \\ University of Khartoum, Faculty of Medicine \\ Moh.Mah.Fadelallah Eljack \\ University of Bakht Alruda, Faculty of Medicine https://orcid.org/0000-0002-2370-9368 \\ Yousif F. O. Altayeb \\ Omdurman Islamic University, Faculty of Medicine

\section{Alshareef B. Nour} \\ Wad Medani College of Medical Science and Technology https://orcid.org/0000-0003-4628-9201 \\ Esraa Hassan Salih \\ University of Khartoum, Faculty of Medicine \\ Abdallah M. Abdallah \\ University of Bahri, Faculty of Medicine \\ Waddah Aljaely Mohammed Osman \\ University of Gezira, Faculty of Medicine \\ Mohammed Yousif Elnaeem Yousif \\ University of Gezira, Faculty of Medicine
}

\section{Research Article}

Keywords: COVID-19, Malaria, Co-infection, Isolation Centers, a Multi-Center, Sudan

Posted Date: January 18th, 2022

DOI: https://doi.org/10.21203/rs.3.rs-1266514/v1

License: (c) (i) This work is licensed under a Creative Commons Attribution 4.0 International License. Read Full License 


\section{Abstract \\ Background}

Malaria and COVID-19 share several characteristics that could lead to cross-infection, particularly in malaria-endemic areas. Early COVID-19 symptoms might be misdiagnosed for malaria in clinical settings. Also, both diseases can cause fatal complications. So, laboratory testing for both diseases was recommended by the WHO.

\section{Objectives}

To study the clinical characteristics and outcomes of Adult Sudanese patients with COVID-19 and Malaria Co-infection.

\section{Methods and materials:}

This retrospective cross-sectional study was conducted from January 2021 to October 2021 in Wad Medani. A total coverage of all Sudanese patients above 18 years old with a confirmed diagnosis of co-infection with COVID-19 and malaria was included, and data was collected using a data collection sheet. Data was analyzed using R software version 4.0.2. Data were described and presented as mean \pm Standard deviation (SD) and number (percentage). To find associated factors with in-hospital outcome, chi-square test, fisher exact test, and independent t-test or Wilcoxon rank-sum test were used.

\section{Results}

In this study, 156 participants were diagnosed with COVID-19 and malaria co-infection. Most of them were between 60-70 years (30.8\%), the majority were males (59\%). Shortness of breath (76.3\%) and acute respiratory distress syndrome (35.3\%) were the most common symptom and complication among co-infected patients, respectively. Ground glass opacity $(n=47 / 49,95.9 \%)$ is the most common result for CT scan. Atrial fibrillation was the most common abnormal ECG finding $(n=6 / 62,9.7 \%)$. Overall mortality among all participants was $(63 / 156,40.4 \%)$.

\section{Conclusion}

High mortality rate was found among the co-infected patients. More attention is needed towards fighting COVID-19 and Malaria co-infection. There may be a link between Malaria and COVID-19.

\section{Introduction}

Malaria is a mosquito-borne infectious disease caused by a plasmodium-like eukaryotic protest ${ }^{1}$. Malaria is one of Africa's most frequent endemic diseases, affecting 250 million people and killing one to three million people, usually children, in Sub-Saharan Africa ${ }^{2}$. P. falciparum, P. vivax, two morphologically identical sympatric species of P. ovale (as suggested by recent data), P. malariae, and the monkey malaria parasite P. knowlesi are the five species known to cause malaria in humans. P. falciparum produces more deadly infections, and patients can quickly develop complications such as severe anemia, acute renal injury, cerebral malaria, spontaneous bleeding and coagulopathy, and others. Its incubation period is about $10-15$ days ${ }^{3}$. In 2020 there were about 241 million cases worldwide, Africa accounts for $95 \%$ of all cases. Southeast Asia is ranked second, followed by the eastern Mediterranean region, which is ranked third ${ }^{4}$. It is one of Sudan's endemic diseases and a severe public health issue. So up to date, almost 1.8 million malaria cases have been documented across Sudan ${ }^{5}$. Fever, headache, generalized fatigability, nausea, and vomiting are typical clinical manifestations of malaria. The severity of an infection is determined by a number of factors, including the plasmodium species, the patient's immunity, and the infected person's overall health and nutritional status ${ }^{6,7}$. Malaria laboratory diagnosis by microscopic thin and thick film, which is the gold standard for malaria identification, as well as fast antigen testing (e.g. Immunochromatography (ICT) and Nucleic acid amplification procedures, may aid in the detection of acute conditions ${ }^{8}$.

SARS-Cov-2 virus, a single-stranded RNA virus belonging to the Coronaviruses family, causes COVID-19. The outbreak began in December $2019{ }^{9}$ in Wuhan, China, and was declared a pandemic in March 2020 because of its rapid expansion ${ }^{10}$. More than 250 million instances of COVID-19 have been verified to date, with a total mortality estimated over 5 million cases. As of the 15th of December 2021, there are 45112 instances in Sudan, with 3252 deaths ${ }^{11}$. When encountered, the major method of transmission is through respiratory droplets from person to person ${ }^{12}$, with an incubation period of about 5 days ${ }^{13}$. COVID-19's most common clinical symptoms are fever and cough. Fatigue, myalgia, headaches, and diarrhea are some of the other common symptoms. The most prevalent laboratory finding is high C-reactive protein, followed by lymphopenia and leukopenia ${ }^{14}$. The real-time polymerase chain reaction (RT-PCR) is a standard approach for diagnosing COVID-19, although its sensitivity is only about $71 \%$, compared to 98 percent for CT chest ${ }^{15}$. Bilateral, peripheral, lower-lobe ground-glass opacities and/or consolidation are typical findings of COVID patients on CT scans ${ }^{16}$. Fever (70 percent-90 percent), dry cough (60 percent-86 percent), shortness of breath (53 percent-80 percent), fatigue (38 percent), myalgias (15 percent-44 percent), nausea/vomiting or diarrhea (15 percent-39 percent), headache, weakness (25 percent), and rhinorrhea (7 percent) are among the most

Page $2 / 13$ 
common symptoms in admitted patients ${ }^{17}$. Pneumonia and acute respiratory distress syndrome are two of COVID-19's most common consequences (ARDS). Additionally, COVID has been linked to acute liver, heart, and renal injury ${ }^{18}$. Age, comorbidities, immunological response, radiographic findings, laboratory data, and signs of organ dysfunction are all characteristics that might help predict the severity of the disease ${ }^{19}$.

Malaria and COVID-19 share several characteristics that could lead to cross-infection, particularly in malaria-endemic areas. Early COVID-19 symptoms, such as fever, myalgia, and exhaustion, might be mistaken for malaria in clinical settings. Adult respiratory distress syndrome (ARDS) is a complication of both of them ${ }^{20,21}$. In the meanwhile, many investigations have found that malaria and COVID-19 co-infection can be diagnosed by positive lab findings for both infections $22,23,24$. As a result, the World Health Organization (WHO) said that the existence of one disease does not imply the absence of the other. This implies the need to do laboratory testing for both disorders ${ }^{25}$.

Approximately 270 million COVID-19 cases have been reported worldwide, with over 5 million deaths. From January 3rd, 2020 , Sudan has around 45 thousand confirmed cases and over 3,000 deaths so far. In 2020, an estimated 241 million cases of malaria will have been reported worldwide, resulting in roughly 627 thousand fatalities, with Africa bearing the brunt of the burden, particularly in the African Sub-Saharan area.

Aside from what has already been stated. Malaria and COVID-19 pose a serious threat to Sudan's already-fragmented health system. In addition, the mutual side effects of each of them add to the difficulty of determining the optimal care regimens for such deadly conditions. There was scarcity in literature regarding this topic, so we aimed at throwing a stone in a pond of water. In this study our aim was to assess the presenting symptoms of malaria and COVID-19 co-infection, to find complications of malaria and COVID-19 co-infection, to describe laboratory, X-ray, CT and ECG findings and to assess the predictors of outcomes of malaria and COVID-19 co-infection.

\section{Methods And Materials}

\section{Study design and area:}

This was a retrospective cross-sectional study which was conducted from January 2021 to October 2021 in Wad Medani (the capital of Gezira state) which is the second largest state in Sudan, with a total population of $4,133,048$. This city, composed of 32 secondary and tertiary hospitals, receives patients from Gezira, Sinnar, Blue Nile, Kassala, Gadarif and White Nile states. Two isolation centers were involved in the study. The first (Soqatra isolation center) composed of 65 beds for mild to moderate cases divided into a general ward (45 beds) and a high dependency unit (HDU) containing

20 beds, 24-hour laboratory, pharmacy and 2 ambulances. The second (Mycetoma center) for critical cases with capacity of 10 ICU beds supplemented with 10 mechanical ventilators and 2 hemodialysis machines in addition to a laboratory, pharmacy and 2 ambulances. The two centers are referral centers that receive patients from all middle, eastern and southern Sudan states (6 states).

\section{Participants:}

We included all Sudanese patients above 18 years old with a confirmed diagnosis of co-infection with COVID-19 by RT-PCR and malaria by microscopy. All patients less than 18 years old or tested negative for COVID-19 were excluded.

\section{Sampling:}

A total coverage for all consecutive patients was done in this study during the period of data collection.

\section{Data collection:}

Data was collected by a well-trained general practitioner using a data collection sheet containing the following items:

1. Demographic data and risk factors.

2. Vital signs (diastolic blood pressure, systolic blood pressure, respiratory rate, pulse and oxygen saturation)

3. Presenting complaints of COVID-19 and malaria.

4. Complication of COVID-19 \& Malaria.

5. Laboratory investigations (WBC, hemoglobin, platelets, lymphocyte, C-reactive protein, creatinine, blood urea nitrogen, D-dimer, random blood glucose)

6. Chest X-ray, CT and ECG findings.

7. Length of stay

8. In-hospital outcome (death or discharge)

\section{Data analysis:}

Data was analyzed using R software version 4.0.2. Data were described and presented as mean \pm Standard deviation (SD) and number (percentage). To find associated factors with in-hospital outcome, chi-square test, fisher exact test, and independent t-test or Wilcoxon rank-sum test were used.

\section{Ethical considerations:}


Ethical approval was obtained from the Ministry of Higher Education, University of Gezira, Gezira state, Sudan. The ethical approval of each center's ethical committee was acquired. Both written and verbal consents were obtained from the participants or their guardians. Privacy and protection of the participant's files and information were of the highest priority.

\section{Result \\ Characteristics of participants}

In this study, 156 participants diagnosed with COVID-19 and malaria co-infection with mean \pm SD of $65.2 \pm 14.5$ participated in this study. Most of them were between $60-70$ years (30.8\%) followed by $71-80$ years $(23.7 \%)$. Nearly half of participants were males (59\%). Hypertension (37.2\%) and diabetes (38.5\%) were the most common risk factors. Mean respiratory rate was $29.8 \pm 9.8$ breaths per minute. All species of malaria were Plasmodium falciparum except one participant with plasmodium vivax (Table 1).

\section{Clinical presentation and complications}

Shortness of breath (76.3\%), and fever (73.1\%) were the most common symptoms among co-infected participants.

Regarding complications, acute respiratory distress syndrome (35.3\%), Thrombocytopenia (16.0\%), and acute kidney injury (8.3\%) were reported as the most common complications of COVID-19 and Malaria co-infection.

\section{Clinical investigations}

Overall mean of total white blood cells and C-reactive protein were $11.5 \pm 8.5$ and $233.3 \pm 746.0$, respectively. Other laboratory investigations were shown in Table 3.

Nearly more than two third of urine samples (82.7\%) were normal. The mean concentration of blood urea nitrogen was $61.6 \pm 43.8$ (Table 3 and 4 ).

Bilateral consolidation was found in more than half of participants who requested chest X-ray $(n=9 / 16,56.2 \%)$. But for CT findings, most participants were having ground glass opacity $(n=47 / 49,95.9 \%)$. ECG findings were found normal in more than half of participants $(n=33 / 62,53.2 \%)$ and atrial fibrillation was the most common abnormal ECG finding ( $n=6 / 62,9.7 \%)$ (Table 4$)$.

\section{Predictors of outcomes}

Overall mortality among all participants was $(63 / 156,40.4 \%)$. Shorter length of stay $(P=0.003)$, usage of respiratory support $(P<0.001)$, presence of acute respiratory distress syndrome $(P<0.001)$, presence of black water fever $(P=0.031)$, and low platelets count $(P=0.035)$ were found significantly associated with death in hospital (Table 1-4).

During using non-parametric tests, increased respiratory rate $(P=0.037)$ and High serum creatinine $(P=0.035)$ were found significantly associated with death in hospital (Table 1 and 3 ).

\section{Discussion}

In this study we report the presenting symptoms and outcome of Adult Sudanese patients co-infected with COVID-19 and Malaria who were admitted to two isolation centers in Wad Madani, Sudan. Understanding clinical features and outcome of COVID19 and malaria co-infections is essential for accurate diagnosis and predictability of treatment when a patient develops complications, in order to alleviate symptoms and reduce morbidity and mortality. To our knowledge, this is the first retrospective observational study providing clinical characteristics and outcome of COVID19 and Malaria coinfection in Sudan, and one of the few in the whole literature. We found that the most common symptoms seen on presentation among co-infected participants include: shortness of breath $(76.3 \%)$ and fever $(73.1 \%)$. We found the overall mortality among all participants to be $40.4 \%$ ( $n=63)$.

During this crisis period, a malaria case may be misclassified as COVID-19 due to symptoms that resemble COVID-19 such as fever, difficulty breathing, fatigue, and headaches of acute onset ${ }^{26}$. At present, given the alertness occurring at the community, health center, nation, regional, and global levels, it is expected that COVID-19 will remain the main target of suspicion; even though co-infection may be present. Sudan faces a number of other infectious diseases that must not be ignored. COVID-19 places additional strain on the already overburdened and resource-constrained health services, which are struggling to keep in check the high burden of existing infectious diseases and non-infectious diseases, such as malaria -which can be misdiagnosed as COVID-19 if it exhibits similar symptoms. Challenges arise from the fact that people with fever are more likely to be tested for COVID-19 and sent home as a result of a negative result, and conversely, febrile patients may be tested for malaria when they are in fact infected with COVID-19; in other words, a patient may be infected with malaria and COVID-19 at the same time, and diagnosis and treatment of one may cause the other to be missed ${ }^{26}$. Malaria has been reported to threaten nearly half of the world's population as of $2018^{4}$. The deadly strain of Plasmodium falciparum malaria poses a challenge because it has the potential to result in severe cases; in Africa, P. falciparum is the most prevalent and deadliest malaria parasite causing the most severe malaria cases overall 27,28 . It's reported in literature that Malaria infections caused by P. falciparum account for approximately $90 \%$ of global Malaria mortality 29,30 . Regarding prevalence of Malaria species in Sudan, the majority (91\%) are cases of severe falciparum infection, while P.vivax accounts for $8(\%)$ cases $^{31}$. Overall Malaria incidence in Sudan was 12.4 percent of all diseases that were reported, over 1.8 million cases are detected with a 13 per 10,000 mortality rate in $2019{ }^{5}$ which is considered low in comparison to the mortality rate (4.8 per cent) in $2002{ }^{32}$.Untreated malaria is a 
leading cause of illness and death in the developing world due to the further infectiousity among community ${ }^{33,34}$. On the other hand, up to 3.58 susceptible individuals can be infected by a single case of COVID-19 ${ }^{35}$. Given that both COVID19 or Malaria can cause severe disease, and both are highly infectious; then, co-infection is expected to occur - especially in areas endemic with malaria like Sudan - and it's expected to be even more fatal than either of the two - COVID19 or Malaria - isolated.

Overall mortality rate of COVID-19 - mono-infection - is approximately $1-14 \%$ in international studies, as well as $7.1 \%$ in Sudan 36,37 . However, the overall mortality rate of a country is not always representative for every state in that country. The majority of COVID-19 cases are in Khartoum state - the capital of Sudan - where the majority of health facilities are available, yet most of the deaths of the disease have been reported from areas outside the capital ${ }^{38}$. Regarding comparison of co-infection mortality rate against mortality rate of COVID-19 isolated-infection; the mortality rate in our study $40.4 \%$ $(n=63)$ - which is done in Gezira state - is comparable to a study done in Al Gadarif state, Eastern Sudan; that showed a high mortality rate of COVID19 - alone - of $37.5 \%{ }^{39}$. And regarding comparison with other co-infection studies, the overall mortality among our co-infected participants was $40.4 \%($ $\mathrm{n}=63$ ), in contrast to a cohort study done in Uganda that showed a mortality rate among COVID-19 and Malaria co-infected patients of only $3 \%{ }^{40}$. We believe that co-infection has a vital role prompting a high mortality rate due to the increased inflammatory response; also, we assume the mortality rate in our study to be inflated due to other factors; such as the lack of fundamental resources (lifesaving resources and adequate staff). P. falciparum overall mortality is difficult to obtain due to scarcity of data; but as stated in a study, P. falciparum mono-infection overall mortality in Sudan, was approximately $0.13 \%$ in $2019^{5}$. It is considered low in comparison with the high mortality of co-infection in our study (40.4\%). The substantial disparity in death rates is most likely related to two factors: one being the long history of endemic malaria in Sudan, that gave most of the community the knowledge, awareness and immunity to avoid further severe infection, in addition to the cumulative experience gained by the health staff regarding responding to the infection; the other factor being the enhanced severity of disease during co-infection.

Other COVID19 co-infections have been documented, for instance, the co-infection of Dengue virus and COVID19 has been reported ${ }^{41}$. Dengue and Chikinguniya - which are two zoonotic arboviral diseases - are endemic in Sudan, as well as malaria ${ }^{42,43}$.Tropical and subtropical countries experience high levels of infection with Dengue virus and Chikungunya virus during the monsoon season, and co-occurrence has been documented ${ }^{44}$.Malaria and dengue virus co-infection, as well as Malaria and Chikungunya virus co-infection have been reported in Sudan ${ }^{43,45}$.A co-infection with any or all of Malaria, Dengue virus, and Chikungunya virus; with COVID19 is predicted during the rainy season due to favorable breeding conditions for the mosquitoes, at the same time as the COVID19 pandemic could have a significant impact on public health ${ }^{46}$.

Fever, cough, and lethargy are frequent symptoms of COVID-1947. Malaria symptoms are many; low-grade fever, shivering chills, and muscle pain, as well as gastrointestinal issues in children, are common first complaints. Such symptoms may appear abruptly, followed by heavy sweats, a high fever, and fatigue ${ }^{48}$.There is scarcity in data regarding COVID-19 and Malaria co-infection, but a study reported that most of the patients with co-infection had fever as a presenting complaint, while some patients had headaches, difficulty breathing and sore throats on presentation ${ }^{49}$. Regarding symptoms among our co-infected patients, we found shortness of breath (76.3\%) and fever (73.1\%) to be the most prevalent symptoms. Our findings align with a study done in Uganda, where fever $(21 \%, n=70)$ and shortness of breath $(19 \%, n=70)$ were the second and fourth most common symptoms among COVID-19 and Malaria co-infected patients, respectively ${ }^{40}$.Although both symptoms are considered among the most to occur, there is a substantial difference between the prevalence of occurrence among the two studies. This might be due to the treatment seeking behavior of our patients, as many individuals wait until symptoms arise before seeking treatment.

As a general rule Covid19 complications are mainly attributed to cytokine release syndrome or a cytokine storm. Complications regarding COVID-19 include: Coagulopathy, Cardiovascular complications and acute respiratory failure ${ }^{50}$. Severe cases may experience dyspnea and hypoxia within a week of the commencement of the illness, which can lead to ARDS or end-organ failure ${ }^{51}$.Acute respiratory distress syndrome produces alveolar damage in the lungs, and the prognosis is worse when COVID-19 is the cause ${ }^{52}$.Concerning complications among our co-infected patients, we found the most common to be acute respiratory distress syndrome, in $35.3 \%(n=156)$ of patients. This is in contrast to a study where the most common complication among COVID-19 mono-infected patients was acute kidney injury followed by probable acute respiratory distress syndrome in $24.3 \%$ ( $\mathrm{n}=73,197)$ and $18.4 \%(n=73,197)$ of patients respectively ${ }^{53}$. The greater percentage in our patients could be ascribed to the enhanced severity caused by the synergistic co-infection pathogenicity effects. Regarding Malaria, the most common pathogenic mechanism is the hemolysis of the Plasmodium-infected red blood cell, which releases plasmodium endotoxin, resulting in high levels of tumor necrosis factor (TNF) generation and findings like fever ${ }^{48}$. Malaria complications are diverse; the most common include: Cerebral malaria, acute renal failure, pulmonary edema, severe anemia, and bleeding ${ }^{54}$. We found Thrombocytopenia to be present in $16 \%(n=156)$ of our patients. This is in contrast to a study, where Thrombocytopenia complicated $41.7 \%$ ( $n=12)$ of COVID-19 and Malaria co-infections ${ }^{55}$.This may be attributed to the difference in sample size and further studies are needed to clarify the ambiguity.

In our patients, the overall concentration of total white blood cells was decreased, and C-reactive protein levels were increased. During malaria, white blood cell (WBC) counts are low or normal, a characteristic that is commonly regarded to represent leukocyte localization away from the peripheral circulation to the spleen and other marginal pools, instead of real deficiency or stasis ${ }^{56}$.In African studies, serum CRP levels have been linked to parasite burden and consequences in malaria, particularly falciparum malaria ${ }^{57}$.In up to 86 percent of severe COVID=19 patients, CRP levels were found to be significantly elevated. CRP levels were much higher in patients with severe disease courses than in mild or non-severe patients, hence it was employed for classification and treatment counseling in severe COVID-19 cases ${ }^{58}$.Elevated D-dimer is a known predictor of COVID-19 infection severity; it's linked to an elevated risk of complications - such as deep vein thrombosis and pulmonary embolism - and is one of the most important determinants of

Page 5/13 
severity ${ }^{59}$.The most common abnormality seen in patients with COVID-19, according to the literature, is sinus tachycardia. Other abnormalities include supraventricular tachycardias like atrial fibrillation or flutter, ventricular arrhythmias like ventricular tachycardia or fibrillation, various bradycardias, interval and axis changes, and ST segment and T wave changes ${ }^{60}$.

Malaria's clinical outcome can be impacted by a wide range of factors, including parasite species, host genetics, innate and acquired immunity, access to adequate treatment, comorbidities, and antimalarial resistance. Infections can lead to various outcomes, such as asymptomatic illness, influenza-like symptoms, and organ dysfunction and death ${ }^{61}$.Regarding COVID-19 outcome, extended hospital admission and greater death can be due to multi-organ failure as well as various metabolic disturbances and respiratory insufficiency, in addition to the multi-system involvement ${ }^{62,63}$.Older age, neutrophilia, and organ and clotting failure (eg, higher LDH and D-dimer) were all linked to the development of acute respiratory distress syndrome in COVID-19 patients hence death ${ }^{51}$. We found acute respiratory distress syndrome to be significantly associated with in-hospital mortality; $63.5 \%$ ( $\left.n=55\right)$ of our patients with acute respiratory distress syndrome died. This is similar to a study where mortality was $52.4 \%(n=84)$ among patients with acute respiratory distress syndrome ${ }^{51}$. The increased mortality rate is probably due to the increased inflammatory response due to the co-infection. Also, we found length of stay of $5.4 \pm 4.3$ days to be significantly associated with in-hospital death $(P=0.003)$; and this is similar to a systematic review wherein terms of overall stay - those who died had a shorter stay than those who were discharged alive ${ }^{63}$.

There is a possibility of a higher rate of COVID-19 co-infections during the ongoing pandemic; especially in areas endemic with infectious diseases like Sudan, hence more efforts should be done to raise the awareness of the community regarding both diseases - COVID-19 and Malaria - in addition to emphasis on the possibility of co-infection between COVID-19 and Malaria in specific, or COVID19 and other infectious diseases in general. A greater clinical suspicion of COVID-19 co-infection should be held; obtaining a correct diagnosis of a treatable infection, and identifying the presence of coinfections requires careful investigation, hence, it would be beneficial to provide malaria testing kits to the COVID-19 testing laboratories, thereby reducing missed opportunities for malaria testing. As a crucial component of helping to solve this difficult conundrum, convenient health infrastructure needs to be prioritized; lifesaving resources and an adequate number of qualified health workers are essential. Further research is needed for identification of etiology as well as better understanding of the pathophysiology behind COVID19 and Malaria co-infection.

Our study had several limitations, first, although our careful approach, the retrospective design in itself increased chances of bias; secondly we selectively included patients with COVID-19 and Malaria co-infection only, without including patients infected with COVID-19 or Malaria mono-infection, so our results cannot be directly compared between patients; lastly, due to inconvenience, we were not able to include isolation centers in other states, so findings cannot be generalized. Despite these limitations, our study has strong points, such as the large sample size of co-infected patients, and diagnostic and immunological tests, in addition to comprehensive laboratory, imaging, and ECG diagnostic techniques, among others.

\section{Conclusion}

Almost 2 in 5 of our participants died with acute respiratory distress syndrome being the most common complication significantly associated with mortality; such a high rate is regarded as a public health concern, and more attention needs to be focused towards fighting COVID19 and malaria coinfection. There may be a link between Malaria and COVID-19, since both diseases present with similar symptoms and complications, resulting in one of them being underdiagnosed therefore -undertreated.

\section{Declarations}

\section{Ethical Approval and Patients' consent:}

Ethical approval was obtained from the Ministry of Higher Education, University of Gezira, Gezira state, Sudan. The ethical approval of each center's ethical committee was acquired. Both written and verbal consents were obtained from the participants or their guardians. Privacy and protection of the participant's files and information were of the highest priority.

\section{Consent for Publication:}

All authors gave their verbal and written consents for publication.

\section{Conflict of interest:}

Authors report no conflict of interest

\section{Funding:}

The Study was funded by authors themselves.

\section{Data availability statement:}

The data that support the findings of this paper is available with the corresponding author upon reasonable request.

\section{Acknowledgments:}


Not applicable.

\section{Authors' contribution:}

$\mathrm{KAH}, \mathrm{EAH}, \mathrm{MSH}$ and MMF: Proposal writing, Building questionnaire and Data collection and Analysis.

YFO, ABN, EHS and AMA: Writing first draft.

WAM and MYE: Did Examinations and Investigations and Supervised the study.

All authors wrote the final draft, revised the final draft and contributed significantly in this study.

\section{References}

1. Koram KA, Molyneux ME. When is "malaria" malaria? The different burdens of malaria infection, malaria disease, and malaria-like illnesses. Am $J$ Trop Med Hyg. 2007;77(SUPPL. 6):1-5.

2. Snow RW, Guerra CA, Noor AM, Myint HY, Hay SI. The global distribution of clinical episodes of Plasmodium falciparum malaria. Nature. 2005;434(7030):214-7.

3. Goddard J, Turner A. Davidson 's. Davidson's principles and practice of medicine. 2014. 461-523. p.

4. World malaria report 2019. World malaria report 2019 [Internet]. WHO Regional Office for Africa. 2019. xxxix, 185 p. Available from: https://www.who.int/news-room/fact-sheets/detail/malaria

5. Keller M. 9.3M 1.1M. 2020;1-6.

6. Clark IA, Rockett KA, Cowden WB. Possible central role of nitric oxide in conditions clinically similar to cerebral malaria. Lancet. 1992;340(8824):894-6.

7. Rieckmann KH. Letters to the Editor Immunochromatographic diagnosis malaria with hypoglycaemia. Lancet. 1996;347:1549-50.

8. Mathison BA, Pritt BS. Update on malaria diagnostics and test utilization. J Clin Microbiol. 2017;55(7):2009-17.

9. Velavan TP, Meyer CG. The COVID-19 epidemic. Trop Med Int Heal. 2020;25(3):278-80.

10. World Health Organization (WHO). WHO Director-General's opening remarks at the media briefing on COVID-19-11 March $2020 \mathrm{No}$ Title [Internet]. 2020. Available from: https://www.who.int/director-general/speeches/detail/who-director-general-s-opening-remarks-at-the-media-briefing-on-covid19-11-march-2020

11. World Health Organization (WHO). WHO Coronavirus (COVID-19) Dashboard [Internet]. 2021. Available from: https://covid19.who.int/

12. WHO. WHO-convened Global Study of Origins of SARS-CoV-2: China Part (14 January-10 February 2021)LI, Q. et al. Early Transmission Dynamics in Wuhan, China, of Novel Coronavirus-Infected Pneumonia. New England Journal of Medicine, v. 382, n. 13, p. 1199-1207,. Jt WHO-China Study Team Rep. 2021;(February):120.

13. Lauer SA, Grantz KH, Bi Q, Jones FK, Zheng Q, Meredith HR, et al. The incubation period of coronavirus disease 2019 (CoVID-19) from publicly reported confirmed cases: Estimation and application. Ann Intern Med. 2020;172(9):577-82.

14. Soltani S, Zakeri A, Rezayat S, Karimi M, Anbaji F, Tabibzadeh A, et al. A systematic literature review on COVID-19, clinical manifestation, laboratory and radiologic features. Adv Hum Biol. 2021;11(1):26.

15. Fang. Pr es s Pr. Lancet [Internet]. 2020;395(3):A1-2. Available from: https://lens.org/019-239-691-300-250\%0Ahttp://dx.doi.org/10.1016/S14733099(20)30120-

1\%0Ahttp://www.ncbi.nlm.nih.gov/pubmed/32155273\%0Ahttps://doi.org/10.1016/j.ijantimicag.2020.105924\%0Ahttp://dx.doi.org/10.1016/S01406736(20)30627-9\%0Ahttp://dx.doi.org/

16. Rodriguez-Morales AJ, Cardona-Ospina JA, Gutiérrez-Ocampo E, Villamizar-Peña R, Holguin-Rivera Y, Escalera-Antezana JP, et al. Clinical, laboratory and imaging features of COVID-19: A systematic review and meta-analysis. Travel Med Infect Dis. 2020;34(January).

17. Mao R, Qiu Y, He JS, Tan JY, Li XH, Liang J, et al. Manifestations and prognosis of gastrointestinal and liver involvement in patients with COVID-19: a systematic review and meta-analysis. Lancet Gastroenterol Hepatol. 2020;5(7):667-78.

18. Anka AU, Tahir MI, Abubakar SD, Alsabbagh M, Zian Z, Hamedifar H, et al. Coronavirus disease 2019 (COVID-19): An overview of the immunopathology, serological diagnosis and management. Scand J Immunol. 2021;93(4):1-12.

19. Chiang S, Salazar-mather TP, Dumenco L, Savaria MC, Su N, Flanigan T, et al. Predictors of COVID-19 severity: A literature review. 2021;31(1):1-10.

20. Since January 2020 Elsevier has created a COVID-19 resource centre with free information in English and Mandarin on the novel coronavirus COVID19. The COVID-19 resource centre is hosted on Elsevier Connect, the company 's public news and information. Int $J$ Infect Dis. 2020;(January).

21. Gennaro F Di, Marotta C, Locantore P, Pizzol D, Putoto G. Malaria and COVID-19: Common and Di ff erent Findings. 2020;

22. Pusparani A, Henrina J, Cahyadi A. Co-infection of COVID-19 and recurrent malaria. J Infect Dev Ctries. 2021;15(5):625-9.

23. Ray M, Vazifdar A, Shivaprakash S, Division H, Foundation SHNR, Reliance SHN, et al. Co - infection with Malaria and Coronavirus Disease - 2019 Over 8000 Macaque Bites Since 2014 but No Herpes B Virus Infection Reported from Shimla, India. 2020;12(3):2019-20. Available from:

https://www.ncbi.nlm.nih.gov/pmc/articles/PMC7733433/

Page $7 / 13$ 
24. Sardar S, Sharma R, Alyamani TYM, Aboukamar M. COVID-19 and Plasmodium vivax malaria co-infection. IDCases [Internet]. 2020;21:e00879. Available from: https://doi.org/10.1016/j.idcr.2020.e00879

25. WHO. Tailoring malaria interventions in the COVID-19 response. 2020;34. Available from: https://www.who.int/malaria/publications/atoz/tailoringmalaria-interventions-covid-19.pdf?ua=1

26. Chanda-Kapata P, Kapata N, Zumla A. COVID-19 and malaria: A symptom screening challenge for malaria endemic countries. Int J Infect Dis. 2020;94:151-153. doi:10.1016/j.ijid.2020.04.007

27. Malaria. Wholnt n.d. https://www.who.int/news-room/fact-sheets/detail/malaria (accessed December 31, 2021).

28. World Health Organization. Management of severe malaria: a practical handbook. World Health Organization, 2000 [29].

29. Snow RW. Global malaria eradication and the importance of Plasmodium falciparum epidemiology in Africa. BMC Med. 2015;13:23. Published 2015 Feb 3. doi:10.1186/s12916-014-0254-7

30. Garcia LS. Malaria. Clin Lab Med. 2010;30(1):93-129. doi:10.1016/j.cll.2009.10.001

31. Wholnt n.d. https://www.who.int/malaria/publications/country-profiles/profile_sdn_en.pdf?ua=1 (accessed December 31, 2021).

32. Abdalla SI, Malik EM, Ali KM. The burden of malaria in Sudan: incidence, mortality and disability-adjusted life-years. Malar J. 2007;6:97. Published 2007 Jul 28. doi:10.1186/1475-2875-6-97

33. Challenger JD, Gonçalves BP, Bradley J, et al. How delayed and non-adherent treatment contribute to onward transmission of malaria: a modelling study. BMJ Glob Health. 2019;4(6):e001856. Published 2019 Dec 10. doi:10.1136/bmjgh-2019-001856

34. Chen I, Clarke SE, Gosling R, et al. "Asymptomatic" Malaria: A Chronic and Debilitating Infection That Should Be Treated. PLoS Med. 2016;13(1):e1001942. Published 2016 Jan 19. doi:10.1371/journal.pmed.1001942

35. Chen TM, Rui J, Wang QP, Zhao ZY, Cui JA, Yin L. A mathematical model for simulating the phase-based transmissibility of a novel coronavirus. Infect Dis Poverty. 2020;9(1):24. Published 2020 Feb 28. doi:10.1186/s40249-020-00640-3

36. Matta S, Chopra KK, Arora VK. Morbidity and mortality trends of Covid 19 in top 10 countries. Indian J Tuberc. 2020;67(4S):S167-S172. doi:10.1016/j.ijtb.2020.09.031.

37. Sudan: WHO Coronavirus Disease (COVID-19) Dashboard With Vaccination Data [Internet]. Covid19.who.int. 2021 [cited 31 December 2021]. Available from: https://covid19.who.int/region/emro/country/sd

38. Sudan [Internet]. Reports.unocha.org. 2021 [cited 31 December 2021]. Available from: https://reports.unocha.org/en/country/sudan/card/48inqdseoY/

39. Omar SM, Musa IR, Salah SE, Elnur MM, Al-Wutayd O, Adam I. High Mortality Rate in Adult COVID-19 Inpatients in Eastern Sudan: A Retrospective Study. J Multidiscip Healthc. 2020;13:1887-1893. Published 2020 Dec 8. doi:10.2147/JMDH.S283900

40. Achan J, Serwanga A, Wanzira H, Kyagulanyi T, Nuwa A, Magumba G et al. Current malaria infection, previous malaria exposure, and clinical profiles and outcomes of COVID-19 in a setting of high malaria transmission: an exploratory cohort study in Uganda. The Lancet Microbe. 2021;3(1):e62e71.

41. Schulte HL, Brito-Sousa JD, Lacerda MVG, Naves LA, de Gois ET, Fernandes MS, Lima VP, Rassi CHRE, de Siracusa CC, Sasaki LMP, Cerqueira SRPS, de Albuquerque CP, Reis APMG, Gomes CM, Kurizky PS, da Mota LMH, Espindola LS. SARS-CoV-2/DENV co-infection: a series of cases from the Federal District, Midwestern Brazil. BMC Infect Dis. 2021 Jul 31;21(1):727. doi: 10.1186/s12879-021-06456-2. PMID: 34332542; PMCID: PMC8325531.

42. Ahmed A, Eldigail M, Elduma A, Breima T, Dietrich I, Ali Y, Weaver SC. First report of epidemic dengue fever and malaria co-infections among internally displaced persons in humanitarian camps of North Darfur, Sudan. Int J Infect Dis. 2021 Jul;108:513-516. doi: 10.1016/j.ijid.2021.05.052. Epub 2021 May 24. PMID: 34044142.

43. Ahmed A, Dietrich I, LaBeaud AD, Lindsay SW, Musa A, Weaver SC. Risks and Challenges of Arboviral Diseases in Sudan: The Urgent Need for Actions. Viruses. 2020 Jan 9;12(1):81. doi: 10.3390/v12010081. PMID: 31936607; PMCID: PMC7019415.

44. Dos Santos S Marinho R, Sanz Duro RL, Santos GL, et al. Detection of coinfection with Chikungunya virus and Dengue virus serotype 2 in serum samples of patients in State of Tocantins, Brazil. J Infect Public Health. 2020;13(5):724-729. doi:10.1016/j.jiph.2020.02.034.

45. Mala W, Wilairatana P, Kotepui KU, Kotepui M. Prevalence of Malaria and Chikungunya Co-Infection in Febrile Patients: A Systematic Review and Meta-Analysis. Trop Med Infect Dis. 2021;6(3):119. Published 2021 Jun 30. doi:10.3390/tropicalmed6030119

46. Ghildiyal, R., \& Gabrani, R. (2021). Computational approach to decipher cellular interactors and drug targets during co-infection of SARS-CoV-2, Dengue, and Chikungunya virus. VirusDisease, 32(1), 55-64. https://doi.org/10.1007/s13337-021-00665-8

47. Guan WJ, Ni ZY, Hu Y, et al. Clinical Characteristics of Coronavirus Disease 2019 in China. N Engl J Med. 2020;382(18):1708-1720. doi:10.1056/NEJMoa2002032

48. Phillips, M. A., Burrows, J. N., Manyando, C., van Huijsduijnen, R. H., van Voorhis, W. C., \& Wells, T. N. C. (2017). Malaria. Nature Reviews Disease Primers, 3. https://doi.org/10.1038/nrdp.2017.50

49. Onosakponome EO, Wogu MN. The Role of Sex in Malaria-COVID19 Coinfection and Some Associated Factors in Rivers State, Nigeria. J Parasitol Res. 2020;2020:8829848. Published 2020 Dec 2. doi:10.1155/2020/8829848

50. Azer SA. COVID-19: pathophysiology, diagnosis, complications and investigational therapeutics. New Microbes New Infect. 2020;37:100738. doi:10.1016/j.nmni.2020.100738

Page $8 / 13$ 
51. Wu C, Chen X, Cai Y, et al. Risk Factors Associated With Acute Respiratory Distress Syndrome and Death in Patients With Coronavirus Disease 2019 Pneumonia in Wuhan, China [published correction appears in JAMA Intern Med. 2020 Jul 1;180(7):1031]. JAMA Intern Med. 2020;180(7):934-943. doi:10.1001/jamainternmed.2020.0994

52. Gibson PG, Qin L, Puah SH. COVID-19 acute respiratory distress syndrome (ARDS): clinical features and differences from typical pre-COVID-19 ARDS. Med J Aust. 2020;213(2):54-56.e1. doi:10.5694/mja2.50674

53. Drake TM, Riad AM, Fairfield CJ, et al. Characterisation of in-hospital complications associated with COVID-19 using the ISARIC WHO Clinical Characterisation Protocol UK: a prospective, multicentre cohort study [published correction appears in Lancet. 2021 Jul 31;398(10298):390]. Lancet. 2021;398(10296):223-237. doi:10.1016/S0140-6736(21)00799-6

54. Trampuz A, Jereb M, Muzlovic I, Prabhu RM. Clinical review: Severe malaria. Crit Care. 2003;7(4):315-323. doi:10.1186/cc2183

55. Wilairatana P, Masangkay FR, Kotepui KU, Milanez GJ, Kotepui M. Prevalence and characteristics of malaria among COVID-19 individuals: A systematic review, meta-analysis, and analysis of case reports. PLoS Negl Trop Dis. 2021;15(10):e0009766. Published 2021 Oct 1. doi:10.1371/journal.pntd.0009766

56. McKenzie FE, Prudhomme WA, Magill AJ, et al. White blood cell counts and malaria. J Infect Dis. 2005;192(2):323-330. doi:10.1086/431152

57. Paul R, Sinha PK, Bhattacharya R, Banerjee AK, Raychaudhuri P, Mondal J. Study of C reactive protein as a prognostic marker in malaria from Eastern India. Adv Biomed Res. 2012;1:41. doi:10.4103/2277-9175.100140

58. Smilowitz NR, Kunichoff D, Garshick M, et al. C-reactive protein and clinical outcomes in patients with COVID-19. Eur Heart J. 2021;42(23):22702279. doi:10.1093/eurheartj/ehaa1103

59. Shah S, Shah K, Patel SB, et al. Elevated D-Dimer Levels Are Associated With Increased Risk of Mortality in Coronavirus Disease 2019: A Systematic Review and Meta-Analysis. Cardiol Rev. 2020;28(6):295-302. doi:10.1097/CRD.0000000000000330

60. Long B, Brady WJ, Bridwell RE, et al. Electrocardiographic manifestations of COVID-19. Am J Emerg Med. 2021;41:96-103. doi:10.1016/j.ajem.2020.12.060

61. Patel H, Dunican C, Cunnington AJ. Predictors of outcome in childhood Plasmodium falciparum malaria. Virulence. 2020;11(1):199-221. doi:10.1080/21505594.2020.1726570

62. Batabyal R, Freishtat N, Hill E, Rehman M, Freishtat R, Koutroulis I. Metabolic dysfunction and immunometabolism in COVID-19 pathophysiology and therapeutics. Int J Obes (Lond). 2021;45(6):1163-1169. doi:10.1038/s41366-021-00804-7

63. Chachkhiani D, Isakadze M, Villemarette-Pittman NR, Devier DJ, Lovera JF. Altered mental status predicts length of stay but not death in a community-based cohort of hospitalized COVID-19 patients. Clin Neurol Neurosurg. 2021;210:106977. doi:10.1016/j.clineuro.2021.106977

\section{Tables}


Table 1: Baseline characteristics, risk factors and vital signs in participants.

Variables N Overall, $N=156^{1}$

\begin{tabular}{|c|c|c|c|c|c|}
\hline & \multirow{2}{*}{\multicolumn{2}{|c|}{$\log 20$}} & & \\
\hline & & & Death, $\mathrm{N}=63^{1}$ & Discharge, $\mathrm{N}=93^{1}$ & \\
\hline Age, years & 156 & & & & \\
\hline Mean \pm SD & & $65.2 \pm 14.5$ & $67.1 \pm 14.4$ & $63.9 \pm 14.6$ & 0.2 \\
\hline Median (Interquartile range) & & $65.0(57.8,75.0)$ & $70.0(60.0,78.5)$ & $65.0(55.0,75.0)$ & 0.11 \\
\hline Age (Groups) & 156 & & & & 0.7 \\
\hline $20-30$ & & $4(2.6 \%)$ & $2(3.2 \%)$ & $2(2.2 \%)$ & \\
\hline $31-40$ & & $4(2.6 \%)$ & $0(0.0 \%)$ & $4(4.3 \%)$ & \\
\hline $41-50$ & & $20(12.8 \%)$ & $8(12.7 \%)$ & $12(12.9 \%)$ & \\
\hline $51-60$ & & $27(17.3 \%)$ & $9(14.3 \%)$ & $18(19.4 \%)$ & \\
\hline $61-70$ & & $48(30.8 \%)$ & $20(31.7 \%)$ & $28(30.1 \%)$ & \\
\hline $71-80$ & & $37(23.7 \%)$ & $16(25.4 \%)$ & $21(22.6 \%)$ & \\
\hline $81-90$ & & $16(10.3 \%)$ & $8(12.7 \%)$ & $8(8.6 \%)$ & \\
\hline Gender & 156 & & & & $>0.9$ \\
\hline Female & & $64(41.0 \%)$ & $26(41.3 \%)$ & $38(40.9 \%)$ & \\
\hline Male & & $92(59.0 \%)$ & $37(58.7 \%)$ & $55(59.1 \%)$ & \\
\hline Marital status & 156 & & & & 0.7 \\
\hline Married & & $131(84.0 \%)$ & $53(84.1 \%)$ & $78(83.9 \%)$ & \\
\hline Single & & $10(6.4 \%)$ & $5(7.9 \%)$ & $5(5.4 \%)$ & \\
\hline Widow & & $15(9.6 \%)$ & $5(7.9 \%)$ & $10(10.8 \%)$ & \\
\hline \multirow[t]{3}{*}{ Length of stay (Duration of illness), days } & 144 & & & & \\
\hline & & $7.0 \pm 5.3$ & $5.4 \pm 4.3$ & $8.1 \pm 5.7$ & 0.003 \\
\hline & & $6.0(3.0,10.0)$ & $4.0(2.0,7.0)$ & $7.0(3.0,10.0)$ & 0.003 \\
\hline Recent Travel history (last 2 month) & 156 & $9(5.8 \%)$ & $6(9.5 \%)$ & $3(3.2 \%)$ & 0.2 \\
\hline Residence & 149 & & & & 0.4 \\
\hline Kordofan state & & $1(0.7 \%)$ & $1(1.7 \%)$ & $0(0.0 \%)$ & \\
\hline Wad Medani & & $148(99.3 \%)$ & $59(98.3 \%)$ & $89(100.0 \%)$ & \\
\hline Occupation & 150 & & & & 0.056 \\
\hline Housewife & & $26(17.3 \%)$ & $12(20.0 \%)$ & $14(15.6 \%)$ & \\
\hline Nonskilled labourer & & $13(8.7 \%)$ & $4(6.7 \%)$ & $9(10.0 \%)$ & \\
\hline Not working & & $65(43.3 \%)$ & $33(55.0 \%)$ & $32(35.6 \%)$ & \\
\hline Professional & & $20(13.3 \%)$ & $4(6.7 \%)$ & $16(17.8 \%)$ & \\
\hline Skilled labourer & & $26(17.3 \%)$ & $7(11.7 \%)$ & $19(21.1 \%)$ & \\
\hline Usage of respiratory support & 152 & $47(30.9 \%)$ & $29(46.8 \%)$ & $18(20.0 \%)$ & $<0.001$ \\
\hline Previous medical history & 156 & & & & \\
\hline Previous hospital admission & & $1(0.6 \%)$ & $1(1.6 \%)$ & $0(0.0 \%)$ & 0.4 \\
\hline $\mathrm{DM}$ & & $60(38.5 \%)$ & $21(33.3 \%)$ & $39(41.9 \%)$ & 0.3 \\
\hline Asthma & & $7(4.5 \%)$ & $4(6.3 \%)$ & $3(3.2 \%)$ & 0.4 \\
\hline COPD & & $2(1.3 \%)$ & $0(0.0 \%)$ & $2(2.2 \%)$ & 0.5 \\
\hline HTN & & $58(37.2 \%)$ & $26(41.3 \%)$ & $32(34.4 \%)$ & 0.4 \\
\hline Immunodeficiency & & $1(0.6 \%)$ & $0(0.0 \%)$ & $1(1.1 \%)$ & $>0.9$ \\
\hline Cancer & & $5(3.2 \%)$ & $2(3.2 \%)$ & $3(3.2 \%)$ & $>0.9$ \\
\hline Recent surgery & & $2(1.3 \%)$ & $0(0.0 \%)$ & $2(2.2 \%)$ & 0.5 \\
\hline Others & & $46(29.5 \%)$ & $24(38.1 \%)$ & $22(23.7 \%)$ & 0.052 \\
\hline Malaria species & 145 & & & & $>0.9$ \\
\hline P. Falciparum & & $144(99.3 \%)$ & $59(100.0 \%)$ & $85(98.8 \%)$ & \\
\hline P. Vivax & & $1(0.7 \%)$ & $0(0.0 \%)$ & $1(1.2 \%)$ & \\
\hline \multicolumn{6}{|l|}{ Vital signs } \\
\hline Pulse rate, beat/min & 149 & & & & \\
\hline Mean \pm SD & & $96.6 \pm 20.5$ & $96.9 \pm 21.1$ & $96.4 \pm 20.1$ & 0.9 \\
\hline Median (Interquartile range) & & $93.0(84.0,107.0)$ & $95.0(86.0,106.0)$ & $90.0(84.0,109.0)$ & $>0.9$ \\
\hline Systolic blood pressure, $\mathrm{mmHg}$ & 150 & & & & \\
\hline Mean \pm SD & & $124.3 \pm 24.5$ & $122.4 \pm 29.5$ & $125.7 \pm 20.4$ & 0.4 \\
\hline Median (Interquartile range) & & $120.0(110.0,140.0)$ & $120.0(109.0,140.0)$ & $130.0(110.0,140.0)$ & 0.2 \\
\hline Diastolic blood pressure, mmHg & 149 & & & & \\
\hline Mean \pm SD & & $73.6 \pm 12.0$ & $71.9 \pm 13.1$ & $74.8 \pm 11.1$ & 0.14 \\
\hline Median (Interquartile range) & & $70.0(70.0,80.0)$ & $70.0(70.0,80.0)$ & $75.0(70.0,80.0)$ & 0.2 \\
\hline Respiratory rate, breath/min & 124 & & & & \\
\hline Mean \pm SD & & $29.8 \pm 9.8$ & $30.7 \pm 7.9$ & $29.2 \pm 11.0$ & 0.4 \\
\hline Median (Interquartile range) & & $28.0(24.0,34.0)$ & $30.0(25.5,34.5)$ & $26.0(22.0,32.0)$ & 0.037 \\
\hline \multicolumn{6}{|l|}{${ }^{1}$ Median (IQR); Mean \pm SD; n (\%) } \\
\hline${ }^{2}$ Wilcoxon rank sum test; Two Sample & & sher's ey te ha & n's Chi-scr & & \\
\hline
\end{tabular}


Table 2: Clinical presentations and complication of COVID-19 and malaria co-in

Variables N Overall, $N=156^{1}$

Outcome

Discharge, $\mathrm{N}=93^{1}$-value ${ }^{2}$

\begin{tabular}{|c|c|c|c|c|}
\hline & & & & \\
\hline COVID-19 and Malaria general symptoms & 156 & & & \\
\hline Fever & $114(73.1 \%)$ & $46(73.0 \%)$ & $68(73.1 \%)$ & $>0.9$ \\
\hline Cough & $104(66.7 \%)$ & $43(68.3 \%)$ & $61(65.6 \%)$ & 0.7 \\
\hline Loss of smell & $0(0.0 \%)$ & $0(0.0 \%)$ & $0(0.0 \%)$ & \\
\hline Nasal obstruction & $0(0.0 \%)$ & $0(0.0 \%)$ & $0(0.0 \%)$ & \\
\hline Loss of taste & $0(0.0 \%)$ & $0(0.0 \%)$ & $0(0.0 \%)$ & \\
\hline Gustatory dysfunction & $0(0.0 \%)$ & $0(0.0 \%)$ & $0(0.0 \%)$ & \\
\hline Sore throat & $3(1.9 \%)$ & $2(3.2 \%)$ & $1(1.1 \%)$ & 0.6 \\
\hline Shortness of breath & $119(76.3 \%)$ & $48(76.2 \%)$ & $71(76.3 \%)$ & $>0.9$ \\
\hline Chest pain & $6(3.8 \%)$ & $1(1.6 \%)$ & $5(5.4 \%)$ & 0.4 \\
\hline Myalgia & $1(0.6 \%)$ & $0(0.0 \%)$ & $1(1.1 \%)$ & $>0.9$ \\
\hline Decrease level of consciousness & $22(14.1 \%)$ & $12(19.0 \%)$ & $10(10.8 \%)$ & 0.14 \\
\hline Headache & $10(6.4 \%)$ & $5(7.9 \%)$ & $5(5.4 \%)$ & 0.5 \\
\hline Chills & $0(0.0 \%)$ & $0(0.0 \%)$ & $0(0.0 \%)$ & \\
\hline Sleep disturbance & $0(0.0 \%)$ & $0(0.0 \%)$ & $0(0.0 \%)$ & \\
\hline Shivering & $0(0.0 \%)$ & $0(0.0 \%)$ & $0(0.0 \%)$ & \\
\hline Nausea & $2(1.3 \%)$ & $1(1.6 \%)$ & $1(1.1 \%)$ & $>0.9$ \\
\hline Vomiting & $11(7.1 \%)$ & $6(9.5 \%)$ & $5(5.4 \%)$ & 0.4 \\
\hline Diarrhoea & $9(5.8 \%)$ & $6(9.5 \%)$ & $3(3.2 \%)$ & 0.2 \\
\hline Others & $18(11.5 \%)$ & $5(7.9 \%)$ & $13(14.0 \%)$ & 0.2 \\
\hline Complications of COVID-19 and Malaria Co-infection & $0(0.0 \%)$ & $0(0.0 \%)$ & $0(0.0 \%)$ & \\
\hline Acute respiratory distress syndrome & $55(35.3 \%)$ & $40(63.5 \%)$ & $15(16.1 \%)$ & $<0.001$ \\
\hline Heart failure & $6(3.8 \%)$ & $1(1.6 \%)$ & $5(5.4 \%)$ & 0.4 \\
\hline Myocarditis & $0(0.0 \%)$ & $0(0.0 \%)$ & $0(0.0 \%)$ & \\
\hline Pulmonary embolism & $2(1.3 \%)$ & $2(3.2 \%)$ & $0(0.0 \%)$ & 0.2 \\
\hline Dizziness & $0(0.0 \%)$ & $0(0.0 \%)$ & $0(0.0 \%)$ & \\
\hline Peripheral neuropathy & $0(0.0 \%)$ & $0(0.0 \%)$ & $0(0.0 \%)$ & \\
\hline Encephalitis & $1(0.6 \%)$ & $1(1.6 \%)$ & $0(0.0 \%)$ & 0.4 \\
\hline Convulsions & $0(0.0 \%)$ & $0(0.0 \%)$ & $0(0.0 \%)$ & \\
\hline Stroke & $3(1.9 \%)$ & $0(0.0 \%)$ & $3(3.2 \%)$ & 0.3 \\
\hline Gillian Barrett syndrome & $0(0.0 \%)$ & $0(0.0 \%)$ & $0(0.0 \%)$ & \\
\hline Acute kidney injury & $13(8.3 \%)$ & $6(9.5 \%)$ & $7(7.5 \%)$ & 0.7 \\
\hline Sepsis & $8(5.1 \%)$ & $5(7.9 \%)$ & $3(3.2 \%)$ & 0.3 \\
\hline Hypoalbuminemia & $1(0.6 \%)$ & $0(0.0 \%)$ & $1(1.1 \%)$ & $>0.9$ \\
\hline Hyponatremia & $1(0.6 \%)$ & $0(0.0 \%)$ & $1(1.1 \%)$ & $>0.9$ \\
\hline Dysenteric malaria & $0(0.0 \%)$ & $0(0.0 \%)$ & $0(0.0 \%)$ & \\
\hline Biliuoric malaria & $0(0.0 \%)$ & $0(0.0 \%)$ & $0(0.0 \%)$ & \\
\hline Choleric malaria & $0(0.0 \%)$ & $0(0.0 \%)$ & $0(0.0 \%)$ & \\
\hline Malaria induced hepatitis & $3(1.9 \%)$ & $2(3.2 \%)$ & $1(1.1 \%)$ & 0.6 \\
\hline Malaria pneumonitis & $2(1.3 \%)$ & $1(1.6 \%)$ & $1(1.1 \%)$ & $>0.9$ \\
\hline Cerebral malaria & $12(7.7 \%)$ & $6(9.5 \%)$ & $6(6.5 \%)$ & 0.5 \\
\hline Black water fever & $9(5.8 \%)$ & $7(11.1 \%)$ & $2(2.2 \%)$ & 0.031 \\
\hline Algid malaria & $4(2.6 \%)$ & $3(4.8 \%)$ & $1(1.1 \%)$ & 0.3 \\
\hline Thrombocytopenia & $25(16.0 \%)$ & $9(14.3 \%)$ & $16(17.2 \%)$ & 0.6 \\
\hline Pulmonary edema & $2(1.3 \%)$ & $1(1.6 \%)$ & 1 (1.1\%) & $>0.9$ \\
\hline Anemia & $11(7.1 \%)$ & $6(9.5 \%)$ & $5(5.4 \%)$ & 0.4 \\
\hline Cerebllities & $0(0.0 \%)$ & $0(0.0 \%)$ & $0(0.0 \%)$ & \\
\hline Gillian Barrett syndrome & $0(0.0 \%)$ & $0(0.0 \%)$ & $0(0.0 \%)$ & \\
\hline Others (Pancytopenia, psychosis, sepsis) & $3(1.9 \%)$ & $0(0.0 \%)$ & $3(3.2 \%)$ & 0.3 \\
\hline $1 \mathrm{n}(\%)$ & & & & \\
\hline${ }^{2}$ Fisher's exact test; Pearson's Chi-squared test & & & & \\
\hline
\end{tabular}


Table 3: Laboratory investigations in participants.

\begin{tabular}{|c|c|c|c|c|c|}
\hline & & 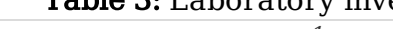 & & & \\
\hline Variables & $\mathbf{N}$ & Overall, $\mathrm{N}=156^{1}$ & Outc & ome & p-value ${ }^{2}$ \\
\hline & & & Death, $\mathrm{N}=63^{1}$ & Discharge, $\mathrm{N}=93^{1}$ & \\
\hline Lab findings & & & & & \\
\hline WBCs counts, $\times 10^{3} / \mathrm{L}$ & 155 & & & & \\
\hline Mean \pm SD & & $11.5 \pm 8.5$ & $11.7 \pm 9.6$ & $11.3 \pm 7.8$ & 0.7 \\
\hline Median (Interquartile range) & & $9.7(6.8,13.4)$ & $9.9(6.9,13.0)$ & $9.6(6.7,13.6)$ & 0.8 \\
\hline Hemoglobin, g/dL & 153 & & & & \\
\hline Mean \pm SD & & $11.9 \pm 2.0$ & $11.6 \pm 2.2$ & $12.1 \pm 1.8$ & 0.13 \\
\hline Median (Interquartile range) & & $12.0(10.6,13.3)$ & $11.7(10.3,13.2)$ & $12.1(10.8,13.4)$ & 0.3 \\
\hline Platelets, $\times 10^{9} / \mathrm{L}$ & 148 & & & & \\
\hline Mean \pm SD & & $248.9 \pm 175.9$ & $212.0 \pm 119.9$ & $274.0 \pm 202.4$ & 0.035 \\
\hline Median (Interquartile range) & & $210.0(134.8,310.8)$ & $194.0(126.8,247.5)$ & $217.0(144.2,350.8)$ & 0.091 \\
\hline Lymphocyte, $\times 10^{3} / \mathrm{L}$ & 116 & & & & \\
\hline Mean \pm SD & & $3.5 \pm 7.3$ & $4.3 \pm 9.8$ & $3.1 \pm 5.4$ & 0.4 \\
\hline Median (Interquartile range) & & $1.2(0.8,2.0)$ & $1.2(0.6,2.0)$ & $1.3(0.9,2.0)$ & 0.5 \\
\hline $\mathrm{CRP}, \mathrm{mg} / \mathrm{dl}$ & 114 & $233.3 \pm 746.0$ & $143.7 \pm 92.2$ & $289.6 \pm 947.6$ & 0.3 \\
\hline Mean \pm SD & & $233.3 \pm 746.0$ & $143.7 \pm 92.2$ & $289.6 \pm 947.6$ & 0.3 \\
\hline Median (Interquartile range) & & $105.5(72.5,200.0)$ & $108.5(83.2,244.2)$ & $93.5(65.2,198.8)$ & 0.3 \\
\hline Creatinine, $\mathrm{mg} / \mathrm{dL}$ & 144 & & & & \\
\hline Mean \pm SD & & $1.7 \pm 2.0$ & $1.8 \pm 1.4$ & $1.6 \pm 2.3$ & 0.5 \\
\hline Median (Interquartile range) & & $1.1(0.9,1.7)$ & $1.2(0.9,2.1)$ & $1.1(0.9,1.5)$ & 0.035 \\
\hline Blood Urea nitrogen, mg/dL & 65 & & & & \\
\hline Mean \pm SD & & $61.6 \pm 43.8$ & $69.5 \pm 41.6$ & $56.0 \pm 45.1$ & 0.2 \\
\hline Median (Interquartile range) & & $49.0(33.0,71.0)$ & $59.0(43.5,76.5)$ & $44.0(32.0,68.5)$ & 0.069 \\
\hline D-dimer, mcg/mL & 113 & & & & \\
\hline Mean \pm SD & & $4,102.3 \pm 3,656.7$ & $4,276.0 \pm 3,916.9$ & $3,974.1 \pm 3,477.6$ & 0.7 \\
\hline Median (Interquartile range) & & $2,510.0(1,200.0,6,939.0)$ & $2,459.4(1,327.8,7,164.2)$ & $2,662.0(1,189.0,6,238.0)$ & 0.7 \\
\hline Random blood sugar, mg/dL & 82 & & & & \\
\hline Mean \pm SD & & $197.9 \pm 118.5$ & $195.9 \pm 105.3$ & $199.5 \pm 129.1$ & 0.9 \\
\hline Median (Interquartile range) & & $158.5(125.2,238.8)$ & $156.5(127.2,228.2)$ & $165.5(120.8,238.8)$ & $>0.9$ \\
\hline SpO2, percentage & 147 & & & & \\
\hline Mean \pm SD & & $79.7 \pm 16.0$ & $76.8 \pm 17.9$ & $81.6 \pm 14.4$ & 0.078 \\
\hline Median (Interquartile range) & & $85.0(72.0,90.0)$ & $80.0(66.0,88.0)$ & $85.0(74.0,92.0)$ & 0.1 \\
\hline 1 Median (IQR); Mean \pm SD & & & & & \\
\hline & & & & & \\
\hline
\end{tabular}


Table 4: Urine analysis, Chest X-ray, CT and ECG findings.

\begin{tabular}{|c|c|c|c|c|c|}
\hline \multirow[t]{2}{*}{ Variables } & \multirow[t]{2}{*}{$\mathbf{N}$} & \multirow{2}{*}{$\begin{array}{c}\text { Overall, } \mathrm{N}= \\
156^{1}\end{array}$} & \multicolumn{2}{|c|}{ Outcome } & \multirow{2}{*}{$\begin{array}{c}\text { p- } \\
\text { value }^{2}\end{array}$} \\
\hline & & & $\begin{array}{c}\text { Death, } \mathrm{N}= \\
63^{1}\end{array}$ & $\begin{array}{c}\text { Discharge, } \mathrm{N}= \\
93^{1}\end{array}$ & \\
\hline Urine analysis & 156 & & & & 0.093 \\
\hline Bilirubin & & $1(0.6 \%)$ & $1(1.6 \%)$ & $0(0.0 \%)$ & \\
\hline Granular cast & & $1(0.6 \%)$ & $1(1.6 \%)$ & $0(0.0 \%)$ & \\
\hline Normal & & $10(6.4 \%)$ & $1(1.6 \%)$ & $9(9.7 \%)$ & \\
\hline Not done & & $129(82.7 \%)$ & $52(82.5 \%)$ & $77(82.8 \%)$ & \\
\hline Protein & & $3(1.9 \%)$ & $2(3.2 \%)$ & $1(1.1 \%)$ & \\
\hline Pus cells & & $7(4.5 \%)$ & $4(6.3 \%)$ & $3(3.2 \%)$ & \\
\hline RBCS & & $1(0.6 \%)$ & $1(1.6 \%)$ & $0(0.0 \%)$ & \\
\hline Sugar & & $4(2.6 \%)$ & $1(1.6 \%)$ & $3(3.2 \%)$ & \\
\hline COVID-19 diagnosis tool & 156 & & & & \\
\hline RT-PCR & & $99(63.5 \%)$ & 37 (58.7\%) & $62(66.7 \%)$ & 0.3 \\
\hline $\mathrm{CT}$ & & $54(34.6 \%)$ & $21(33.3 \%)$ & $33(35.5 \%)$ & 0.8 \\
\hline Clinical & & $13(8.3 \%)$ & $7(11.1 \%)$ & $6(6.5 \%)$ & 0.3 \\
\hline Chest Xray findings & 16 & & & & 0.019 \\
\hline Bilateral consolidation & & $9(56.2 \%)$ & $0(0.0 \%)$ & $9(75.0 \%)$ & \\
\hline $\begin{array}{l}\text { Bilateral infiltration + suspected diaphragmatic hernia + lung } \\
\text { collapse }\end{array}$ & & $1(6.2 \%)$ & $0(0.0 \%)$ & $1(8.3 \%)$ & \\
\hline Bilateral peripheral lung consolidation & & $1(6.2 \%)$ & $1(25.0 \%)$ & $0(0.0 \%)$ & \\
\hline Cardiomegaly + Right side consolidation & & $1(6.2 \%)$ & $1(25.0 \%)$ & $0(0.0 \%)$ & \\
\hline Congestion + consolidation & & $1(6.2 \%)$ & $1(25.0 \%)$ & $0(0.0 \%)$ & \\
\hline Midzone bilateral consolidation & & $1(6.2 \%)$ & $1(25.0 \%)$ & $0(0.0 \%)$ & \\
\hline Right side middle lobe consolidation & & $1(6.2 \%)$ & $0(0.0 \%)$ & $1(8.3 \%)$ & \\
\hline Right side pleural Effusion & & $1(6.2 \%)$ & $0(0.0 \%)$ & $1(8.3 \%)$ & \\
\hline Respiratory investigation COVID related CT chest & 49 & & & & \\
\hline Ground grass opacity & & $47(95.9 \%)$ & $21(100.0 \%)$ & $26(92.9 \%)$ & 0.5 \\
\hline Pleural effusion & & $1(2.0 \%)$ & $0(0.0 \%)$ & $1(3.6 \%)$ & $>0.9$ \\
\hline Patchy or lobar consolidation & & $3(6.1 \%)$ & $1(4.8 \%)$ & $2(7.1 \%)$ & $>0.9$ \\
\hline Alveolar congestion and fibrotic change & & $1(2.0 \%)$ & $0(0.0 \%)$ & $1(3.6 \%)$ & $>0.9$ \\
\hline ECG findings & 62 & & & & 0.035 \\
\hline Atrial fibrillation & & $6(9.7 \%)$ & $6(23.1 \%)$ & $0(0.0 \%)$ & \\
\hline Atrial tachycardia & & $1(1.6 \%)$ & $1(3.8 \%)$ & $0(0.0 \%)$ & \\
\hline Complete heart block & & $1(1.6 \%)$ & $0(0.0 \%)$ & $1(2.8 \%)$ & \\
\hline Hyperacute T-wave & & $1(1.6 \%)$ & $0(0.0 \%)$ & $1(2.8 \%)$ & \\
\hline Left anterior descending artery occlusion & & $5(8.1 \%)$ & $2(7.7 \%)$ & $3(8.3 \%)$ & \\
\hline Left anterior descending artery occlusion bradycardia & & $1(1.6 \%)$ & $1(3.8 \%)$ & $0(0.0 \%)$ & \\
\hline Left anterior descending artery occlusion $+\mathrm{R}$-wave in $\mathrm{v} 1$ & & $1(1.6 \%)$ & $1(3.8 \%)$ & $0(0.0 \%)$ & \\
\hline Left bundle branch block & & $3(4.8 \%)$ & $1(3.8 \%)$ & $2(5.6 \%)$ & \\
\hline Normal & & $33(53.2 \%)$ & $11(42.3 \%)$ & $22(61.1 \%)$ & \\
\hline Q-wave & & $1(1.6 \%)$ & $1(3.8 \%)$ & $0(0.0 \%)$ & \\
\hline Q-wave + T-wave & & $2(3.2 \%)$ & $0(0.0 \%)$ & $2(5.6 \%)$ & \\
\hline Right axis deviation & & $2(3.2 \%)$ & $1(3.8 \%)$ & $1(2.8 \%)$ & \\
\hline ST segment elevation & & $1(1.6 \%)$ & $0(0.0 \%)$ & $1(2.8 \%)$ & \\
\hline ST Segment elevation & & $2(3.2 \%)$ & $1(3.8 \%)$ & $1(2.8 \%)$ & \\
\hline T wave inversion & & $1(1.6 \%)$ & $0(0.0 \%)$ & $1(2.8 \%)$ & \\
\hline T wave inversion + left ventricular hypertrophy & & $1(1.6 \%)$ & $0(0.0 \%)$ & $1(2.8 \%)$ & \\
\hline $1 \mathrm{n}(\%)$ & & & & & \\
\hline${ }^{2}$ Fisher's exact test; Pearson's Chi-squared test & & & & & \\
\hline
\end{tabular}

